\title{
Reflections of Black Women Academics at South African Universities: A Narrative Case Study
}

\author{
Matseliso Mokhele \\ Department of Curriculum and Instructional Studies, \\ University of South Africa (UNISA), Pretoria 0003 South Africa.
}

\section{Doi:10.5901/mjss.2013.v4n3p611}

\section{Abstract}

A substantial body of research has established that women academics are under-represented both nationally and internationally with regard to research activity. The issues and obstacles faced by Black women that impede their full participation in the higher education sector are not new. They are old issues that have not yet been fully acknowledged, discussed and resolved (Henry and Glenn 2009). The literature suggests a number of possible factors which lie behind women's less than impressive research profile such as the fact that women have less discretionary time to conduct research, write papers and attend conferences, particularly if they have dependent children or other caring responsibilities. The long hours associated with research production are hugely gendered. Few women, however, have managed to succeed in spite of this gendered problematic of research in higher education. Even fewer black women, though, have succeeded to establish a research career in South Africa. The present study was undertaken within the context of one university research organisation in the post-apartheid South Africa, where the legal impediments for the success of black women researchers would be expected to have been removed. The major purpose was to explore the narratives of women academics in research, especially Black women who, for the most part have continued to be marginalised in the academe. The paper discusses the experiences of one senior black woman researcher at one large higher education institution in South Africa. Using the black feminist theories as my framework, I examine the various impediments, both personal and structural that mitigate against women's careers as researchers within the higher education institutions. I conclude the paper by arguing for the need to pay more critical attention to the institutional and structural impediments in order to address more directly the problem of marginalisation of women researchers within South African higher education.

\section{Introduction}

Building a research profile is arguably the most essential element for achieving success as an academic in a higher education environment, not only for the purpose of intellectual prestige, but also for reasons of economic survival. An examination of the research on women in higher education, however, suggests that the marginalisation of women scholars and administrators, with varying degrees of success and disparities is a global phenomenon (Mabokela 2011). Rees (2005) also asserts that research is deeply gendered, both in the methods favoured by men and topics selected for research funding; men dominate research committee decisions, editorial boards and informal academic networks. A large scale survey conducted by Blake and La Valle (2000) confirmed the observation that women's research careers are less developed than men's. They also found that a woman's professional profile was less likely to include a high publication record or involve a set of high profile academic activities or sometimes they were also less likely to be holding a PhD.

The Report on Women and Research (2010) also states that many women also have caring and other timeconsuming commitments outside of work, which limits their ability (compared to many men) to focus on the academic research necessary to compete and to build successful academic careers. In contraction counter-argument though, Williams (2009) maintains that family responsibilities should not be seen as "mitigating circumstance" but should rather be seen as part of life for women. If we take seriously Williams caution not to view family responsibilities as an impediment, then what other factors may be limiting women's career development as researchers? Viewed differently, we may also want to investigate other ways in which women can and do negotiate family responsibilities in favour of their career development as researchers.

More recently, as agued by Aguirre (2000), researchers have documented the findings that women of colour encounter more barriers to professional socialisation and success in the academic workplace than do their white female counterparts. In the South African context, white women were privileged by legal prescriptions during the pre-1994 historical phase, thus putting them above black women in the hierarchical ordering of the peoples of South Africa then. 
Black women therefore suffered dual oppression - the oppression of being black women in the segregated political system and the oppression from the patriarchal Africa culture (Henry and Glenn 2009). How have things changed in higher education, if at all, post the 1994 democratic elections in South Africa? The present study is undertaken within the context of one university and research organisation in South Africa. The major purpose of the study is to explore the narratives of women academics in research, especially Black women who, for the most part have continued to be marginalised in the academe. According to Morley, et al (2006), the national plan for Higher Education drawn up by the department of Education in South Africa in 2001 makes explicit comments on the under representation of black and female staff in Higher Education within the country. With this in mind, I therefore found it imperative to investigate the experiences of specifically Black women in education research. In order to explore the experiences of women researchers, I explored what are the obstacles that affect black women in starting and maintaining their research career? What structures and practices might prevent black women from starting and maintaining their research career? What structures and practices support black women in starting and maintaining their research career?

Mabokela (2011) makes a disturbing observation about the continued absence of black woman scholars in the knowledge production arena. She notes that research and publishing are still dominated by the male scholars at historically white (advantaged) universities, the majority of whom are white.

For black women and other women of colour in the academic workplace, marginalisation often translates into a feeling of invisibleness. Other researchers have also documented a multitude of barriers encountered by black female students, faculty, and staff (Henderson 2005). Contemporary research continues to reveal that issues of racial and gender inequality remain extremely salient features, more especially for Black women (Hughes and Howard-Hamilton 2003).

According to Henry and Glenn (2009) Black women also continue to suffer ostracism from their colleagues and supervisors. Patitu and Hinton (2003) also revealed similar patterns of isolation among the black women faculty and administrators. In their study, they reported that women experienced marginalisation and lack of support from both their peers and managers. This is in addition to the phenomenon observed by Ismail (2011) who presents data to show how many black and female staff are employed at the lower ranks in both academic and administrative posts.

In the South African context where people were differentiated, privileged or underprivileged on the basis of their skin colour, the gender debate should be viewed as embedded, in the first instance, in the racial divisions that characterise our past. White women were privileged by legal prescriptions during the pre- 1994 historical phase, thus putting them above black women in the hierarchical ordering of the peoples of South Africa then. On the contrary, black women suffered dual oppression-the oppression of being black women in the segregated political system and oppression from the patriarchal Africa culture. It follows therefore that against this background research on the experiences of black women academic in South Africa is needed and timely.

In South Africa affirmative action laws have been in place since the Employment Equity Act came into effect in 1999. It aims to promote equal opportunity and fair treatment in the workplace by eliminating unfair discrimination on any grounds, and through affirmative action measures that redress historical disadvantages suffered by "designated groups"among them black people, women and the disabled. However, as Shackleton et al (2006) asserts, while equity laws and policies cover the all disadvantaged groups, in South Africa, race comes to the fore and other groups fall off the platform, affirmative action has not worked at all. As she puts it, "there is always a reason why someone else is better, or has more experience." In their research Morley et al (2006) shows how informants in South Africa report how their strong national policy framework for transformation does not always translate into positive changes for individuals and groups in their daily lived experiences. Many researchers, including Mabokela (2001), Mabokela and Mawila (2004) and Moultrie and de la Rey (2003) have all undertaken research on women academic positions in South Africa, and reported on how black women are still profoundly disadvantaged, and underrepresented. Black universities, where the numbers of black women are better are teaching institutions and lack a research culture, having been set up to train administrators mostly for the black homelands, and therefore keep the system in place, rather than become seats of knowledge.

\section{Theoretical Framework}

In this study, I have employed Black feminist thought as an appropriate framework for exploring the experiences of Black women academics. The bases of Black feminist thought are rooted in studies of the different feminist's voices that have questioned, exposed, and provoked debate on the conditions of black women in the United States (Osada and Conceicao da Costa 2009). According to Howard-Hamilton (2003) the theory provides an appropriate framework which adds an important element of depth to our understandings about the struggles and needs of Black women in academia. It rejects 
the notion of universal laws of behaviour, favouring idiosyncratic approaches by focussing on individual functioning, goals and meaning within Black female realities (Stephens and Phillips 2005). This theory, as argued by Collins (2000) is the theory that stems from the need to make the lives of Black women (and other women of colour) visible, to tell their stories from their point of view and in their own words, and to work on their behalf for justice and empowerment. As a result, the theory is more appropriate in this research as my aim was to explore the experiences of the black women academics in South African institutions of higher education.

The primary focus of the Black feminist theory is to foster both Black woman's empowerment and conditions of social justice. Collins (2000) goes on to note that Black feminist thought places the ideas and experiences of Black woman at the centre of analysis. According to Collins (2000) there are four theses inherent within Black feminist thought. Firstly, "The lived experiences as criteria of meaning" which refers to the knowledge Black women gains as a result of their life experiences. Secondly "The use of dialogue," it suggests the importance of establishing bonds and relationships since oppressive and contentious events is seldom solved in isolation. Thirdly, "The ethic of caring theme", it incorporates the use of expressiveness, emotion and empathy as a means for greater understanding of the Black women's unique experiences. Fourthly, "Ethic of personal accountability", it refers to knowledge claims which lack objectivity. The Black feminist thought is therefore the relevant theory to apply for the purpose of this study as it is important in assisting Black university women researchers to effectively deal with the wide array of microagressive indignities (racist attitudes and behaviours) encountered in their daily campus experiences (Howard-Hamilton 2003). In summary, Black feminist thought formed the basis of the theoretical lens through which the experiences of the Black woman academics who participated in this study were viewed.

\section{Methodology}

The purpose of this study was to explore the experiences and perceptions of the Black women academics regarding research. To find out specifically what are the obstacles that affect black women in starting and maintaining their research career. The study was therefore designed as a narrative case study. I employed narrative analysis, in order to help me understand meanings of the women's lives and to look at and describe experiences, ideas, beliefs and values of participating black women academics. Narrative was more suited to help me in understanding the participants in terms of their own definitions of their world. To collect the required data for the study, I conducted narrative interviews with a total number of 5 black women academics in two different institutions of higher learning. Permission was sought from the professors and each one completed the required consent forms prior to our conversations. The sample was made up of all the black women professors of education at two historically white higher education institutions who were willing to be interviewed. The sample was chosen partly out of convenience and curiosity about the challenges of black women professors at my own institution and one other comparative institution with a similar number of black women education professors. A Semi-structured interview schedule was used to allow for a detailed investigation of the life stories and reflections of the professors. In this paper I tell the story of one black professor of education, Professor Jeannie, as an illustrative case of the kinds of struggles and negotiations that black professors engage with as they seek to craft a career as researchers within the higher education institutions of South Africa.

\section{Findings of the study}

I present the interview data from the conversations I had with Professor Jeannie.

\subsection{Background}

Professor Jeannie is a 57 year old black woman academic, who was born and raised in one of the rural provinces of South Africa. Currently, she is a well developed researcher and an experienced top manager in an academic institution. In her early years, she had always wanted to become a teacher since she was four years old:

On becoming a teacher, I think I am one of the most unusual people because many people that I have taught with or that I have met said they landed in teaching because they could not get this or that.....for me from the time I was 4 years old I just liked to be a teacher

As she explains in the quotation above, her interest in teaching did not come by mistake as is the case with other people she taught with who landed in teaching just because they could not find other opportunities other than teaching. 
Indeed, even while Professor Jeannie is a research manager at one of the top institutions in the country, she still talks very fondly about her days as a teacher at various high schools across the country.

\title{
1.2 Jeannie's Education
}

For Jeanie to get educated was not a surprise, not even to herself because of her family influence and status. She felt that she was influenced greatly by the family environment that she grew up in. basically, her mother who was a qualified school teacher and her father, an attorney; played a much bigger role in shaping her views and aspirations about getting an education. Prof. Jeannie comes from a very well educated family with a long ancestry of well educated and politically active members. As it turned out, her grandparents were also highly educated.

My mother was a teacher, my father an attorney, my grandfather and grandmother were highly educated, so I come from the family of educated people so there was never ever a question for me that I would study

Prof Jeannie believes that having come from a well educated family like that of her own, there was no doubt that she would also get educated. For her, the importance and play out of "cultural capital" couldn't be as clear as was the case in her own upbringing.

Immediately after completing her high school, Prof Jeannie was certain that she wanted to go to the university and study for a degree at one university in her province. In spite of the challenges she experienced in the university environment, such as frustrations on choosing the course she wanted to do, she finally completed her B.A degree in three years time, and began her teaching career. A year later, Jeannie was back at the same university to study further for the B.A. (honours) degree before going back to teaching again.

\begin{abstract}
After completing high school, I knew I had to go to the university; it was so frustrating, I did not know what university is was all about; because I found all these "ologies" I had never seen before. All I knew was about subject that I liked which were languages; I did not know anyone who had majored in languages, so I completed my form with sociology, anthropology, all ready wanted was to do English and Izixoza, anyway I finally finished my B.A. after teaching I went back to Bimbo university to do the B.A (hons) then I went back to teaching again
\end{abstract}

\subsection{Jeannie's post graduate Education}

While teaching at a secondary school, Jeannie saw an advert in one of the local newspapers where one of the universities in the city wanted to fund masters degree students in comparative literature. Jeannie did not hesitate. She found this to be an opportunity, not only for her to continue with her advanced studies but also to finally find her way out of the rural province to the city. She took up the placement into a Masters programme in education, which after completion she immediately went back to teaching. This time, however, she found herself a teaching post in one of the secondary schools in the city. She taught for a few years in that secondary school, before she was invited by a friend to submit a job application in one of the new teachers' colleges which was looking to fill a lecturer post. So, after about three years of teaching experience in the city secondary school, Jeannie set off to become a lecturer at the teacher' college.

Otherwise coming here which is now more than 30 years ago, I just needed to get out of Transkei, I saw an advert. UNIVER University was advertising for people to do masters in comparative literature, so I applied and that is how I came to Gauteng.

\subsection{Jeannie's experience in the USA}

Jeannie worked as a lecturer at the college for a few years before yet another opportunity came knocking at her door, so to speak. She was awarded a scholarship to go and study in the United States of America. Initially, she wanted to go and study for an advanced certificate in education in the UA. She was advised that non degree certificates were not catered for, and was therefore advised to re- apply to study for a PhD, even though she had not planned or decided she needed the doctoral degree.

My going to the USA, well I did not plan to do a phd, I applied to do advanced certificate, so when I went for an interview, then they told me afterwards, "we don't fund none degree studies, but they did not dismiss me, they said I can go and re-work the application and apply for PhD 
While she had not bargained on studying for a PhD, Jeannie was however, grateful to have received such an opportunity to study for a PhD abroad. Jeannie felt that she grew a lot in terms of her academic development in general. One of the great experiences for her in the USA was the opportunity to attend and participate in the doctoral seminars which was and still is not a common practice within the South Africa universities. Jeannie found these doctoral seminars to be a great eye opening opportunity because they allowed her "to sharpen her content knowledge before she could get deeper in her own research work". Jeannie will forever be grateful for having got a chance to study in the USA as she believed that she gained more experience in terms of academic work and personal development and also with the fact that she was also a full time student who did not have to worry or think about other responsibilities but, just to show up in the seminars. She was also funded and so did not have to worry about the finances doe her studies.

So that is how I landed in the USA, but I am ever grateful that I got that opportunity. I did not think I needed it, I did not want to do any Phd, I was finally very happy, I just think I learned a lot about myself, grew academically, grew world wise

\subsection{Jeannie's return from the USA and her career in the academic world}

Jeannie's return from the US was not as easy as she had thought, while she continued to work at the college where she was a lecturer before going to the US she also went all out job hunting, the reason, she strongly believed that for unknown reasons her rector did not like her, after all he was the new rector and wanted her out of the job.

On my return from the U.S. .....I was applying around because I think my rector did not really like me to be there, it was new rector....... don't think he was very happy with me, for the reasons, I do not know

She finally found the posts advertised in one of the universities and she applied and that's how she began her journey as a senior lecturer in the university. Jeannie did not have much of the problem in terms of teaching at the university as she had been a teacher before. However, there were a number of hardships that Jeannie went through. First of all, she worked as she explained it, in a very white university (historically white university), and to be more specific, a white faculty, male dominated. In her faculty, there were only six of them who were black with only two of the females including her. All of them were in a more junior positions, she was the only one who was a senior lecturer as she was a senior lecturer in her former workplace (the college). Not many of the staff members had their Phd degrees, in fact amongst all the six black staff members; she was the only one with a Phd degree. She also explains how everybody was suspicious and questioned her Phd, especially her white colleagues who did not have PhDs themselves. She believes that they had their ideas that, "everybody passes in the US"

There were about 6 of us, black people, so it was a white university, a white faculty, it was Afrikaans speaking, staff meetings and whatever were held in Afrikaans and they were not flexible. Many of the whites were professors and male predominately, it was not an environment one would want to work in, they were also suspicious about my Phd, they had their idea that "everybody passes in the USA"

She however, mentions how no matter how hard it was, (unlike her black colleagues who never questioned anything), she stood her grounds and clarified her position, and she was as a result known or named "anti-Afrikaans".
I was the only black who had a doctorate and I knew my position, I felt that these others were taken chance of because they were junior and did not have PhD and so they could not question things. For me these people were not my supervisors so, I stood my grounds and I think that irritated people the reason I was later named "anti-Afrikaans"

One of the biggest challenges was that of the language (Afrikaans), many of the conversations were in Afrikaans and many of the faculty meetings were also held in Afrikaans, this resulted in her finding it difficult to settle fully in the university and where she really felt that she was underprivileged compared to her white counterparts. She therefore decided to join the Black transformation forum and because of her active participation, she was appointed a chairperson of the language committee.

I think for me, the greatest challenge was the language that was really frustrating especially when you look at your white female colleagues and think, if they could understand the language then they were more privileged than us, it was not a friendly environment all, I found it hard to survive and I even joined the Black Forum and was appointed the chairperson of the language committee and the vice president of the Black Forum 
In her career as a lecturer in this university Jennie had a great difficulty with publishing, not only difficulty but also not knowing where and how to start, as a result, she felt lonely and extremely frustrated. She was however, in the long run, finally invited by one of the woman professors to write a chapter in a book, she therefore found an opportunity to even use the sections from her phd work. She was also later introduced to her critical reader from another university. She later got more of the invitations to submit her research work in the university journals which actually gave her confidence to begin to write more, as well as the funding to attend and present her work at the different conferences.

\begin{abstract}
I was not publishing, I did not know how to......it was not easy at all, it was frustrating, I still hate the fact that I could not get into publishing immediately, but finally one of the white professors, Jane invited me to write a chapter in teaching, at least I was able to finally use my thesis, I was also introduced to someone who was to be my critical reader, some colleagues even invited me to attend conferences
\end{abstract}

She concluded that one needed a helping hand in order to make it, and that if she was never invited she could have never been able to publish not even from her own thesis, she felt that she was in the difficult and foreign environment and that one would need people to invite him/her and give guidance. She mentioned how everything was difficult simply because they were no official/formal mentors or supervisors. She was only fortunate to have found people who simply volunteered and became helpful to her.

\begin{abstract}
As I said, it was gradual, I would say you really needed someone, if a few of the colleagues had not invited me , I would have never been able to publish or know anything about the conference, so you need someone to hold you by hand and unfortunately my fellow black colleagues were all at very junior positions, I felt lonely, it was difficult, it was foreign, even if you had been intelligent or something. You really needed people. I felt that I was fortunate to have got those who helped me, because we did not have mentors, it was just about people being helpful
\end{abstract}

\title{
1.6 Jeannie the dean
}

Jeannie was later promoted to a position of an associate professorship, however, the promotional positions were only open to the black people to advance, regardless of this rule, Jeannie was one of the people who was not promoted immediately and had to fight her way in, until such time when she was officially promoted as an associate professor.

When I became an associate professor er........ it was a position open for the whole university only to black people to advance black people, so we had applied, infect I did not even get the position immediately, Thabo and I did not the promotion immediately there were things that had to be challenged before we were promoted

She later became a dean, and that was even before she was promoted into a full professor. The position of the dean had actually come during the transformation phase, when things became to change for better in the university; the position was pushed by black forum for black people. Jeannie was therefore encouraged by her black colleagues to apply for the position as she was also the vice president of the black forum.

I became the dean while I was an associate professor before I was a full professor, that was just a transformation thing, and that now things were changing, it's not as if I had planned to be a dean or wanted to be a dean, it was a position that was just being pushed by black people at the black forum, I was at that time the vice president of the black forum

Before she even started her journey as the dean of the faculty, Jeannie still encountered some challenges, first of all before she was appointed as a dean there was a serious commotion where the white colleagues wanted their own dean and the black forum wanted her as a dean.

During all this process, the white colleagues pushed for Ella as she was acting dean and they were asking how could I apply while I had not even been an HOD,......... it was something that was not straight forward and there was meetings after meetings after our interview, the black people pushed for me.

It was not an easy battle but she was finally appointed as a first black woman dean of the faculty, happy but scared she wondered if she would cope.

I was finally appointed, I was so scared, wondering where I was going to start, what am I going to do? I did not even want to go work, because I could imagine the hatred people had towards me. 
She concluded that as much as she was hated by her white colleagues she was later well supported by almost everyone except a few of her black colleagues who felt they had fought for her but when she is on board she forgets about them.

Few blacks that were specifically not promoted because they did not qualify resented me and stopped talking to me and even reported me to the council that I am now pro-white, all whites are advantaged and so on!

Other than this, in her position as a dean unlike when she was at the lecturer level, she got much of the support, like the structure that was set up for the deans to be oriented and introduced to a number of things within the institution. The position has also helped her to grow in terms of who the players in the institutions are as well as giving her opportunity to voice out her views, network with other stakeholders as well as to represent the university whenever she could. She also felt good that finally she could represent blacks, she could represent woman, she could represent black woman and with the understanding and experience of what they were going through. Professor Jeannie concluded that in spite of all the challenges she had a number of people who greatly supported her, more especially her family members as well as her friends and other colleagues from the faculty, and that such support gave her the strength to go on in spite of the difficult circumstances. She believes it was not an easy road but notes that some people have to go first to clear the road for the coming generation.

\section{Discussion and Conclusion}

In this section, I highlight four themes that emerge from the case study of Professor Jeannie.

\subsection{The Power of Lived Experience}

The narrative of Professor Jeannie begins to illustrate how a young black woman grows and develops into being a senior professor within the academe in South Africa. True to the themes in the black feminist thought, Jeannie's narrative captures how her own lived experiences as a black woman from a rural village in the Eastern Cape, who acquires a doctoral degree from one of the major universities in the USA becomes a textbook for her to learn about being a researcher in Higher Education. In most contexts, negotiating the academic programme from undergraduate through to a $\mathrm{PhD}$ could have been enough to enable one to start off on the fast track to academic success. An important condition for success is that early recruitment and recognition by those already within the academy. The early entry and guided mentoring experience is often critical to success as an academic. The narrative in this case draws attention to the challenges involved during early recruitment and growth period. In the case of Professor J, she had live to live through a further initiation and growth period as a new, young and black academic in a previously whites-only institution in South Africa. Those life experiences were not natural or easy to negotiate but seem to have provided an added set of lessons for her towards her professorship. In describing how she made alliances and partnerships with women of other races in her department, to navigate through the seemingly male dominated maze of challenges during her earlier years at the $\mathrm{HEI}$, Jeannie further exemplifies what Collins (2000) calls the "use of dialogue" by black women. This is how Jeannie deals with one of the existential barriers for young, black women academics especially within the South African context, that of isolation.

\subsection{Isolation as a Black, Women and Senior Academic}

Jeannie described how being black, and new at the HEl created suspicion not only around her as a person but, also around her qualifications and competence. Many of her colleagues were doubtful of her and what she stood for in terms of scholarship. Being black in predominantly white institutions could not have been easy, especially during the early years of South Africa's transition to democracy post-1994. The likes of Jeannie were almost lonely and isolated as many of the academics continued with their normal business of trying to churn out more and more articles and research papers as required in their performance agreements. Nowhere, in the performance agreements were academics required to work with others and socialise them into the academy. According to Zamani (2003), studies reveal co-occurring discrimination related to race and gender, including lack of supports systems and networks (Patton and Harper 2003) as well as an unwelcoming, insensitive and isolative environment (Watt 2003). Significantly, though, Professor Jeannie did not only have to contend with suspicions around who she was as a black person, but she also had to deal with suspicions from male academics (including black males). She was a woman after all, and at the time all the senior positions in her faculty 
were occupied by white men. Isolation as a black scholar and as black woman constitutes a critical barrier that is highlighted in the present narrative. Secondly, Jeannie was not only a young black academic but rose to become a senior scholar (professor) a position that deepened the isolation. As a senior professor, not only was it difficult to interact with other colleagues in the department, but also some of the young black scholars kept a safe distance for fear of threading to closely to the Dean. It is interesting to note also how Jeannie had to deal with suspicions of academic qualifications and competence as some of her colleagues began to cast down on the American PhD. Once more, issues of rigor and quality in terms of qualifications are not by themselves subversive, and therefore questions around credentials could sometimes be tolerated. The problem with such questions arises when they are coupled to other devices for isolation and become a reinforcing mechanism for exclusion. The case of Jeannie therefore illustrates clearly how isolation works in practice to conspire against the success of black women researchers in the South African context.

\subsection{Communities of Practice and the Supportive 'Other'}

Earlier we referred to the use of dialogue by Professor Jeannie, where she described how she made alliances with women of other races to enable her to build friendships and networks. She was able to learn a great deal from some of the more experienced colleagues, even though they were of different races and cultures. Jeannie's story is about finding the bridges for these networks and sharing. Similarly, Professor was lucky to have been part of a network of black academics at the university - the Transformation Forum - where black scholars could come together and exchange notes in supporting one another. It is evident from the narrative what a big role the Transformation Forum played in her life at the institution and how supported and enabled her rise to senior professorship. While the case could be made for a black forum of this nature to support young black academics, it is more the lessons of having the space and platform to network, share experiences, and be affirmed by other scholars in similar conditions as oneself that is more important. It is quite conceivable that one person could easily become a member of several such networks in one's career journey.

\subsection{Raw Courage}

While one's life experiences are helpful in preparing one to overcome obstacles, as well as Communities of Practice to break the isolation of black women academics, and to provide the necessary networks and collective resources for support, it is in the final analysis raw courage that seems to have played in decisive role for Jeannie. Instead of feeling pity for herself, in the situation that she found herself in, Jeannie was very clear about what she wanted to achieve and it would seem like nothing would stand in her way. It was her courage to leave teaching and travel to the USA for postgraduate study, to return and join a historically white university as a senior lecturer, and become not only the first black woman professor in the faculty but also its first black Dean that we need to understand more deeply. While further research still needed on the personal (e.g. courage) and how it plays out in the academic trajectory, this paper has highlighted the importance of paying attention to the institutional factors that play out to isolate and thereby limit the growth and development of black women researchers in higher education.

In the case of Jeannie, it was not the case of having unsupportive family structures, including children and other maternal roles, that made it difficult to succeed as an academic. To the contrary, Jeannie describes a set of fairly supportive family conditions. The most pervasive factors in the case of Jeannie were more institutional than personal. The institutional structures and practices are therefore more significant in accounting for the lack of progress for the likes of Jeannie at the present $\mathrm{HEl}$ and probably others that are similar.

If it is the case that institutional structures and practices are more significant in stunting the growth of black women researchers, then there is some hope. There is hope for change, provided that there is a will to tackle institutional cultures and structures more vigorously than has been the case since the dawn of democracy in South Africa. Sadly, though, institutional cultures have not changed much post-1994 among many South African universities and the results are obvious in the relatively negligible number of black women professors in all the HEls in South Africa. As Hughes and Howard-Hamilton 2003 asserts, it is imperative that colleges and universities take active role in establishing connective programming that decreases the obstacles that Black women contend with on daily basis.

\section{References}

Aguirre, A. 2000. Academic Storytelling: A Critical Race Theory Story of Affirmative Action. Sociological Perspectives, 43(2): 319-339. Black, M and La Valle, I. 2000. Who applies for research funding? Key Factors Shaping Funding Application Behaviour Among Women and Men in British Higher Education Institutions. London, UK. 
Collins, PH. 2000. Black feminist thought. New York: Routledge

Henry, W and Glenn, N. 2009. Black women employed in the ivory tower: Connecting for success. Advancing Women in Leadership Journal, 27(1).

Henderson, CE. 2005. When and where I enter: Black women in the academy. http://www.diverseeducation.com/artman/publish larticle_5266.shtml

Howard-Hamilton, M. F. 2003. Theoretical frameworks for African American women. In M. F.

Howard-Hamilton (Ed.) new directions for student services. Meeting the needs of African American women ,104,:19-28. San Francisco, CA: Jossey-Bass.

Hughes, R.L and Howard-Hamilton, M. F. 2003. Insights: Emphasizing issues that affect African American women. In M. F. HowardHamilton (Ed.), New directions for student services. Meeting the needs of African American women (pp 95-104). San Francisco, CA: Jossey-Bass.

Ismail, S. 2011. researching transformation at a South African university-ethical dilemmas in the politics of representation, Studies in Higher education, 36(3): 275-289.

Mabokela, R. O and Mawila, FNK. 2004. The impact of race, gender and culture in South African higher education, Comparative Education review, 48(4): 396-416.

Mabokela, R.O. 2001. Hear Our Voices!: Women and the Transformation of South African Higher Education The Journal of Negro Education, 70(3): 204-218.

Moultrie, A and de la Rey, C 2003. South African women leaders in higher education professional development needs a changing context, McGill Journal of education, 38(3): 407-420.

Morley, L., Gunawardena, C., Kwesiga, J., Lihamba, A. Odejide, A. Shacketon, L.,Sorhaindo, A.

Osada, N. M and da Conceição da Costa M. 2009. "Black Feminist Thought: Knowledge, Consciousness, and the Politics of Empowerment; Patricia Hill Collins-DOI: 10.3395/reciis. v2i2. 221pt." RECIIS 2.2

Patitu, C.L and Hinton, K.G. 2003. The experiences of African American women faculty and administrators in higher education: Has anything changed? In M. F. Howard-Hamilton (Ed.), New directions for student services. Meeting the needs of African American women 104: 79-93). San Francisco: Jossey-Bass.

Patton, L. D. and Harper, S. R. (2003). Mentoring relationships among African American women in graduate and professional schools. In M. F. Howard-Hamilton (Ed.), Meeting the needs of African American women. New Directions for Student Services, 104: 67-78.

Rees, T. 2005, Keynote address at the 4th European Conference on Gender Equality in Higher Education, Oxford Brookes University, Oxford, September.

Shackleton, L. Riordan, S. and Simonis D. 2006. Gender and the transformation agenda in South African higher education. In Women's studies international forum, 29(6): 572-580.

Stephens, D.P and Phillips L. 2005. Integrating Black feminist thought into conceptual frameworks of African American adolescent women's sexual scripting processes. Sexualities, Evolution, and Gender, 7(1): 37-55.

Watt, S. K. 2003. Come to the river: Using spirituality to cope, resist, and develop identity. New Directions for Student Services, 104: $29-$ 40.

Zamane, EM 2003 African American women in higher education. In M.F. Howard-Hamilton (Ed), new directions for student services. Meeting the needs of African American women Vol. 104, 5-18. San Francisco, CA: Jossy-Bass. 
